\title{
Skeletal evidence of osteoarthritis: a palaeopathological perspective
}

\author{
Robert D Jurmain, Lynn Kilgore
}

Osteoarthritis (OA), or degenerative joint disease, is the most common form of joint pathology, and it has an extensive history. Indeed, it has been observed in a variety of fossil animals, and has been reported in the fossil remains of dinosaurs. ${ }^{1}$

Among preindustrial human groups, as documented by skeletal remains, osteoarthritic changes are quite frequently the most common pathological lesion seen. Such degenerative changes have been described for archaeological samples varying widely in time and location. ${ }^{2-8}$ In many cases, ${ }^{9-15}$ frequencies of involvement have also been calculated and presented.

Skeletal evidence from archaeological sites thus has potential to expand considerably the range of epidemiological data concerning OA. Human populations long since extinct can be sampled. Current epidemiological data are limited almost entirely to clinical samples drawn from urban contexts, mostly from North America and Europe. Earlier populations, ranging from arctic hunters, to early RomanoBritish agriculturists, to Mediaeval Nubians (and, obviously, many others) may have led lifestyles very different from those characteristic of contemporary groups. Accordingly, skeletal analysis provides a 'window' into a vastly broader sample of human groups than afforded solely by clinical samples. If varying levels of mechanical loading are important in the aetiology of OA, as suggested by the 'stress hypothesis', ${ }^{16}$ earlier populations could be expected to exhibit definitive patterns of joint involvement. Such patterns should be reflected in differential involvement both within and among joints; moreover, patterns of bilateral asymmetries, sex based variation, and perhaps, most crucially, clearly demarcated frequencies of involvement among prehistoric populations should be manifest.

Department of Anthropology, San Jose State University, San Jose, CA 95192, USA $R$ D Jurmain

Department of Anthropology, Colorado State

University,

Fort Collins,

CO, USA

CO, USA

Correspondence to: R D Jurmain. seen. Presumably slight arthritic involvement includes small marginal lipping (osteophytes) or small erosive changes to the joint surface itself. In modern contexts, such minor bone involvement is not usually recognised as it does not present radiographically; occasionally, following surgical replacement, a few macerated specimens have become available, ${ }^{17} 18$ thereby giving researchers a rare glimpse of underlying bony tissue.

In addition, materials derived at postmortem are a most useful supplement and help bridge the gulf between clinical data and fully macerated remains. Several detailed studies have, in fact, investigated the frequency of $\mathrm{OA}$ in postmortem collections. ${ }^{19-21}$ Moreover, in a few cases large numbers of macerated specimens have carefully been obtained from dissecting room samples and have been curated as permanent collections (most notably, the Todd Collection at the Cleveland Museum of Natural History and the Terry Collection at the US National Museum of Natural History). These collections have proven a rich source of information, as the skeletons are virtually intact, sex and age (approximated) were recorded at the time of dissection, and for many individuals cause of death (and some clinical history) is also noted. Building upon this rich data source, skeletal biologists ${ }^{2} 920$ have used dissecting room skeletal collections to refine their descriptions of osseous degenerative lesions, and to make epidemiological comparisons with other groups.

For archaeologically derived specimens there are tens of thousands of examples of remodelled joint surfaces. Moreover, when skeletal materials are well preserved, numerous regions can be systematically observed, including the large peripheral joints, the vertebral column (body surfaces in addition to apophyseal articulations), and the numerous small articulations of the hands and feet. In this way, a pattern of involvement within individuals and, more generally, within populations can be established.

Finally, in addition to a palaeoepidemiology of degenerative arthritis in human groups, such comparative perspectives can be expanded to include non-human animals. Recent work with non-human primates, ${ }^{22}{ }^{23}$ especially the study of joint involvement in great apes, ${ }^{24-26}$ has opened the potential for an even broader perspective concerning the aetiology of osteoarthritis. By studying animals with differing postural/locomotory adaptations and correlating these factors with the pattern of degenerative lesions, we should be able to gain a fuller understanding of some of the mechanical factors influencing the aetiology of OA. 


\section{Methodological approaches}

Degenerative lesions of joints are most commonly evaluated in skeletal materials using ordinal scaling (most frequently, as none/ slight; moderate; severe). Criteria usually include both marginal changes (osteophytic development) and articular surface changes (pitting, eburnation, or both). In fact, many researchers ${ }^{27} 28$ argue that the most reliable diagnostic criteria for osteological determination is a combination of marginal changes accompanied by articular surface alterations. Additionally, in some studies $^{29}$ periarticular areas of tendinous insertions (for example the greater and lesser tubercules of the humerus) have also been evaluated.

Finally, evaluation of radiographic alterations, most importantly subchondral remodelling, has also been attempted; however, few systematic results have emerged here, so
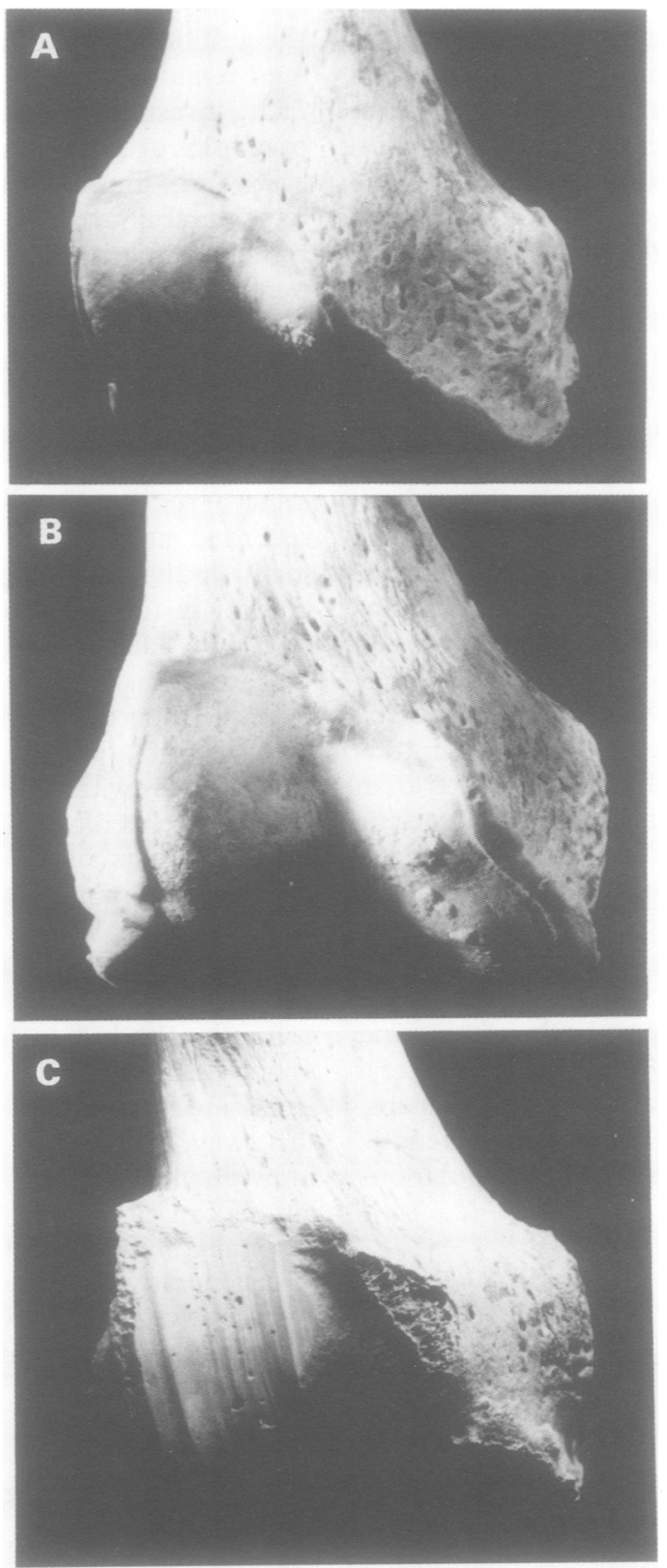

Figure 1 Stages of osteoarthritis as shown in the knee. A: Slight involvement with small marginal osteophyte. $B$ : Moderate involvement with larger marginal osteophyte. $C$ : Severe involvement, showing large osteophyte and eburnated, grooved articular surface. that, with few exceptions, ${ }^{28}$ radiographic study of skeletal OA has not yet become routine. Figure 1 shows an example of the scoring of the stages of OA of the knee.

PERIPHERAL INVOLVEMENT

Evaluation of the large peripheral joints (particularly the shoulder, elbow, hip, and knee) by osteologists has been undertaken more commonly and systematically than for other regions of the body. Most commonly, the degree of OA involvement has been reported as a single value for an entire joint (for example the shoulder). This observed level of involvement is derived from assessment of the individual articulations (for example glenoid of scapula, head of humerus) and usually reported as the greater (more severe) score. ${ }^{13} 1430$

In a few, more detailed, investigations, individual areas within joints have been scored separately. ${ }^{91131}$ For example, in a study of dissecting room samples of Black and White Americans (Terry Collection) compared with two archaeological samples, ${ }^{29}$ numerous specific areas within joints were evaluated: seven variables for the shoulder; 16 for the elbow; 10 for the hip; and 17 variables in the knee. For each side of the body, therefore, a total of 50 variables were evaluated, yielding a maximum of 100 variables per individual. As an example, the table shows a list of these regional indicators of skeletal OA for the elbow joint.

Scoring the osteoarthritic changes in such a specific fashion allows a more comprehensive interpretation of arthritic involvement within particular joints. For example, do marginal changes occur independently of articular surface degeneration? Do functional components within joints (for example patello-femoral $v$ femoro-tibial) act somewhat independently? Does age interact differentially as a factor within various joint segments?

Another advantage of using multiple indicators per joint (as opposed to a single average value) is that the values can be more easily manipulated statistically. Ordinal measures, such as those used almost universally for skeletal assessment of OA, are not parametric. Thus most of the more robust types of statistical analyses cannot, strictly, be applied. However, as the number of individual variables

Specific areas scored for degenerative joint involvement in the elbow

\begin{tabular}{ll}
\hline Variable & $\begin{array}{l}\text { Ordinal } \\
\text { scoring } \\
\text { range }\end{array}$ \\
\hline Distal humerus, trochlea, medial margin & $0-2$ \\
Distal humerus, trochlear ridge & $0-2$ \\
Distal humerus, capitulum, lateral margin & $0-2$ \\
Distal humerus, olecranon fossa & $0-2$ \\
Distal humerus, coronoid fossa & $0-2$ \\
Distal humerus, trochlea, articular surface & $0-3$ \\
Distal humerus, capitulum, articular surface & $0-4$ \\
Proximal ulna, coronoid process, margin & $0-2$ \\
Proximal ulna, olecranon process, margin & $0-3$ \\
Proximal ulna, radial facet, margin & $0-1$ \\
Proximal ulna, coronoid process, articular surface & $0-2$ \\
Proximal ulna, olecranon process, articular surface & $0-2$ \\
Proximal ulna, radial facet, articular surface & $0-2$ \\
Proximal radius, head, superior articular surface & $0-4$ \\
Proximal radius, head, inferior margin & $0-2$ \\
Proximal radius, head, lateral articular surface & $0-2$ \\
\hline
\end{tabular}


increases (giving a much wider dispersion of values), the total joint score approaches the conditions of parametric normality. Accordingly, analyses such as analysis of variance comparing degree of degenerative joint involvement with bone density ${ }^{32}$ can be facilitated.

\section{VERTEBRAL INVOLVEMENT}

Within the vertebral column the fibrocartilagenous joints of adjoining vertebral bodies are usually scored exclusively on the basis of marginal osteophytes (and the lesion is thus called vertebral osteophytosis or spondylosis). Figure 2 shows comparative stages of vertebral osteophytosis. Although these fibrocartilagenous joints are not synovial, the processes of degenerative arthritis that occur here are superficially similar to those seen in true synovial joints. Owing to these similarities in gross involvement, in some palaeopathological reports there is confusion relating to terminology. In this paper we follow the clinical consensus and reserve the term 'osteoarthritis' for synovial joint involvement, while vertebral body involvement is referred to separately as 'vertebral osteophytosis.'

Most commonly, in evaluating vertebral osteophytosis the entire body suface is given a single score, ${ }^{133}$ but in some studies the margin was subdivided into more specific regions (anterior, anterolateral, posterior). One researcher ${ }^{34}$ has attempted to calculate metrically the degree of osteophyte development.

For apophyseal OA, the nature of degenerative changes tends to be very subtle, manifested as a slight thickening around the joint margin or sharp edged pitting of the articular surface. Until now, few systematic attempts have been made to standardise the methodology.

\section{Limitations of the osteological approach}

AGE DETERMINATION

The lack of precision in determining age at death for human skeletal remains imposes a major limitation on osteological analyses of OA. As this disease is clearly age correlated, comparisons among different groups (or between males and females within groups) cannot be accomplished without accurate determination of the age structure of the respective populations. Here lies the difficulty. Even though attempts have been made to characterise systematically the progressive age changes in human skeletons, ${ }^{35-37}$ for adult skeletons the deteminations are still only rough approximations. The most reliable age indicator involves progressive remodelling of the pubic symphysis, but as a well documented contemporary sample from the Los Angeles County Coroner's Office has shown, ${ }^{37}$ the age estimates from the pubic symphysis can be established only within broad age brackets ( \pm 10 years, or more); and, even more
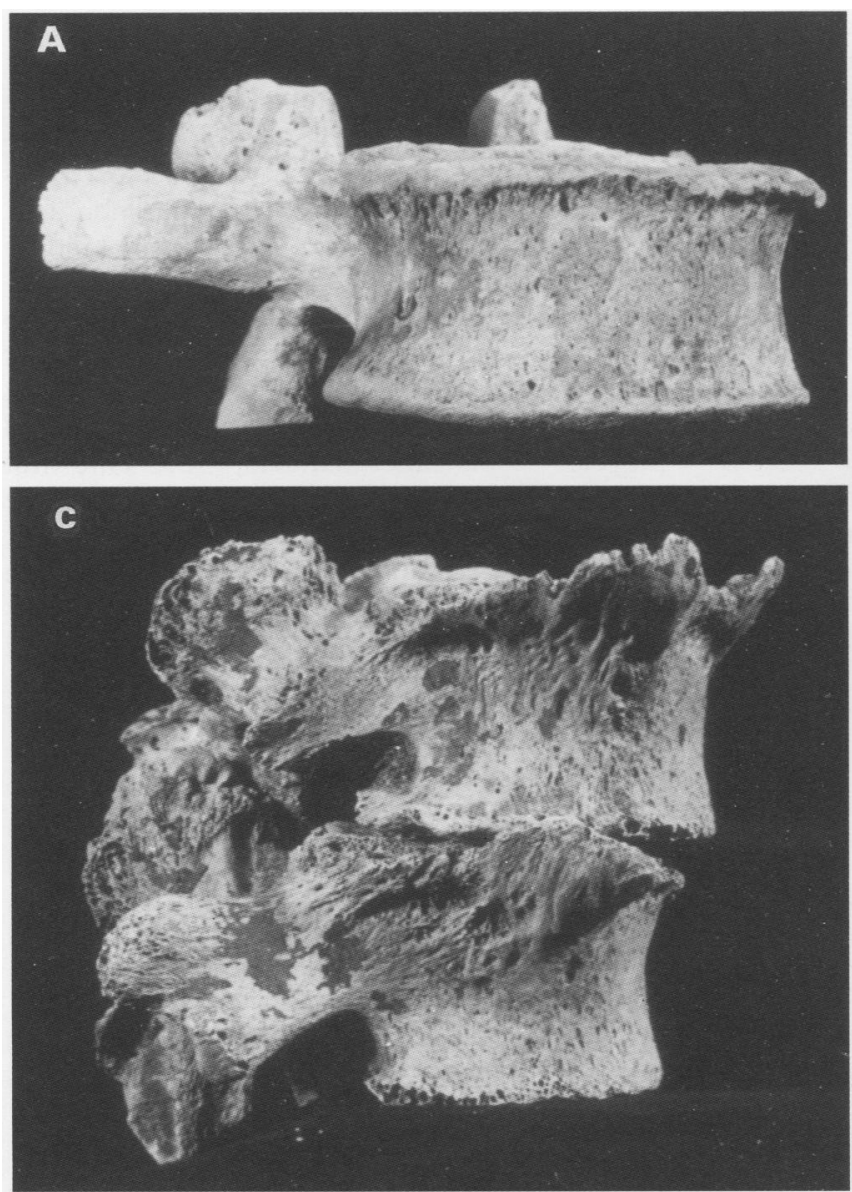
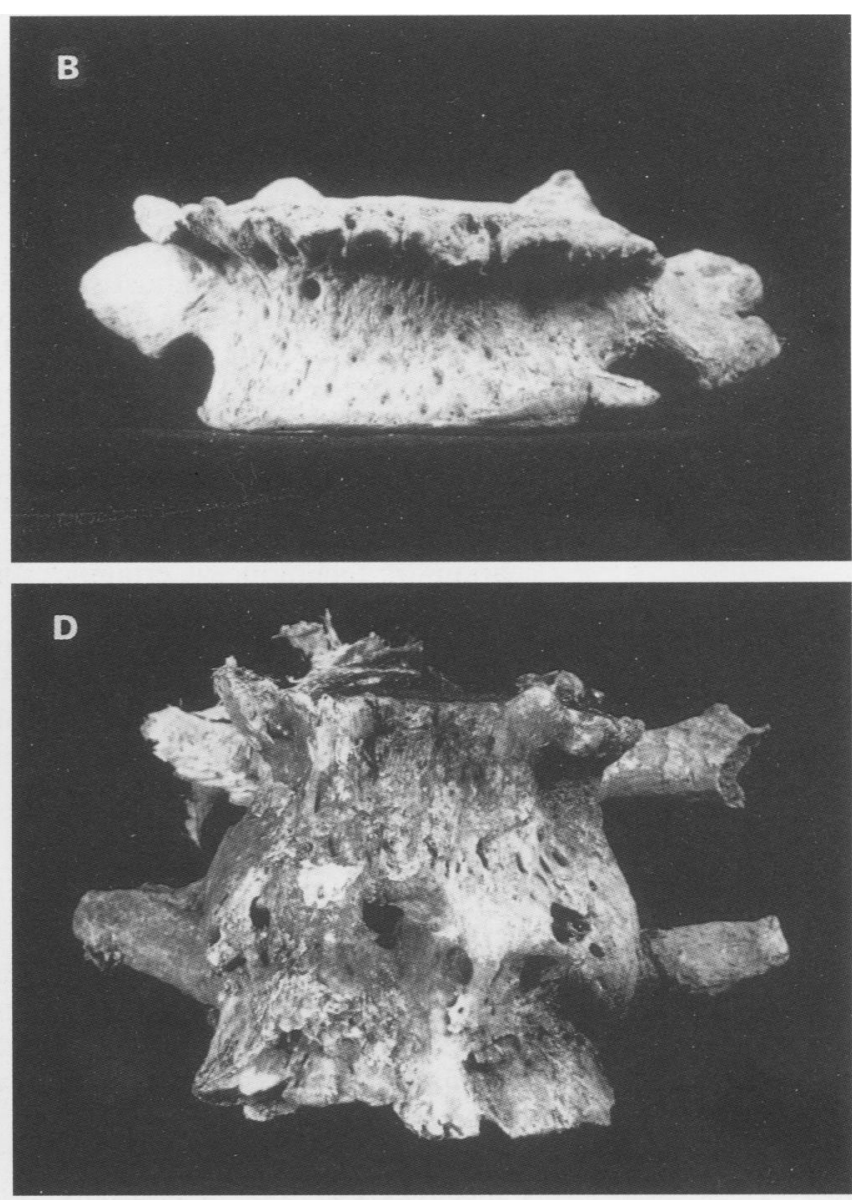

Figure 2 Stages of vertebral osteophytosis. A: Slight. B: Moderate. C: Severe. D: Ankylosis. 
disturbing, as age increases, the estimates become even less precise.

Other age approximations of older adults, such as calibration of cranial suture closure, have not proved as accurate as changes at the os pubis, and thus are not routinely used. However, some recent innovations, including evaluation of remodelling of the auricular surface of the ilium ${ }^{38}$ or sternal ends of the ribs $^{39}$ have proved useful, at least for some skeletal groups.

One approach that has sought to control for the lack of precise age control in archaeological materials is to utilise contemporary macerated samples. As mentioned above, such dissecting room samples as the Todd and Terry collections have been regularly used by skeletal biologists, including studies of degenerative joint disease. ${ }^{9}{ }^{40}$

\section{CLINICAL CORRELATION}

Another obvious limitation in skeletal research on archaeologically derived materials is the lack of clinical records for any of the individuals. Without information regarding symptomatology the assumption has been that at least some of the osteological changes observed (osteophytes or articular surface remodelling) relate to pain or other symptoms during life. For OA of the peripheral joints, the moderate and severe changes regularly scored by osteologists probably do relate to a degree of impaired function. ${ }^{41}$ Some, although as yet small scale, efforts have begun to assemble materials to correlate clinical records with hard tissue alterations. These collections, derived as surgically removed macerated specimens, ${ }^{17} 18$ probably provide the best means to address this constraint.

STANDARDISATION OF SCORING

Another problem that must still be resolved by skeletal biologists doing research on degenerative joint disease is the current lack of systematic scoring criteria. While all researchers use some ordinal scaling system and look at basically equivalent bony changes (osteophytes, porosity, eburnation of surface), little has been agreed upon in terms of standardisation of technique. Certainly, some greater degree of standardisation is desirable. At present, researchers are reasonably confident that, at least for moderate and severe changes (which are easily recognisable), reasonably comparable criteria are generally being applied.

\section{HISTORICAL DOCUMENTATION}

Another unavoidable, yet major, difficulty that arises with archaeological material is the poor quality of general ethnographic information for the groups represented. Certainly, ethnohistorical data can be of some use-for example, activities of Inuit arctic hunters ${ }^{11}$ or mediaeval Nubian agriculturists. ${ }^{13}$ However, even here, the degree of precision relating to specific types of behaviours practised by these peoples is very superficial.
Even more limiting, we have almost no idea of the actual intensity of the significant mechanical loadings involved, or their duration, in the activities of early populations. Some modern data suggest that duration of mechanical stress may be crucial-for example, the observation that degenerative elbow involvement appears only after three to 10 years of use of pneumatic tools. ${ }^{42}$

\section{BEHAVIOURAL INTERPRETATIONS}

From comparisons among various ancient populations of the frequency and severity of osteoarthritic changes, skeletal biologists have routinely sought to draw conclusions relating to presumed behavioural factors. However, given the only very superficial nature of the behavioural data which are available, such conclusions must be regarded as extremely tenuous. Indeed, extreme caution must be used in evaluating much of the osteological literature on OA, including early publications by the authors. ${ }^{9} 10$ These investigators begin with the assumption that culturally patterned mechanical stress leads to the onset of OA; moreover, the differences in frequency and severity of involvement within groups (males $v$ females) are explained by such differences in behaviour, as are most of the differences between groups.

Following along these logical lines, these investigators then peruse the limited ethnohistorical documentation in order to isolate those presumed activities that initiated the degenerative disease (such as rowing among the Inuit or use of the hoe in Nubians). It is clear that such reasoning is largely circular, but it nevertheless continues to persist in the literature. ${ }^{43}$ Certainly, on the basis of currentlyavailable data, the conclusions are virtually untestable.

The wisdom that extreme caution should be exercised in not too quickly making functionally based explanations of $\mathrm{OA}$ is attested to in the clinical literature. Some, largely anecdotal, data have suggested some links with activity, for example in the ankles of football players $^{445}$ or ballet dancers, ${ }^{45}$ the elbow of some pneumatic tool users, ${ }^{46}$ or spinal disease in coal miners and longshoremen, ${ }^{46}{ }^{47}$ yet other studies have found no such conclusive evidence relating strenuous activity to any increase in $\mathrm{OA}$ in the lower limb of physical education teachers, ${ }^{48}$ the elbow of other pneumatic tool users, ${ }^{49}$ or in the leg of parachutists. $^{48}$

Given the quite mixed results of contemporary epidemiological attempts to establish a firm correlation between specific activities and increased incidence of $\mathrm{OA}$, any such attempts extended to the much less well documented archaeological past represent an extremely hazardous intellectual venture.

\section{Analyses of degenerative disease in} human skeletons

Anthropologists, anatomists, and others have long been interested in the patterning of 
degenerative disease as seen in fully macerated or partially mummified human remains. As early as 1911 , Ruffer and Rietti ${ }^{50}$ described several examples of arthritic disease in ancient Egyptians. For many years much of the focus was centred on vertebral lesions, especially vertebral osteophytosis. ${ }^{23} 33$ In the past few decades, however, attention has also been shifted to describing the distribution of lesions in the large peripheral joints. ${ }^{8911} 1314$ In addition, some researchers have also reported on the temporomandibular joint. ${ }^{13} 3051$ To date, however (with few exceptions ${ }^{30} 33$ 52) little systematic analysis of the small joints of the hands and feet has been accomplished.

\section{Osteoarthritis of the peripheral skeleton}

A basic approach applied to the interpretation of skeletal series borrows much from contemporary epidemiological methodology. Such an approach, when utilised for archaeologically derived materials, is usually termed 'palaeoepidemiology.' As in epidemiological surveys, the most useful data are derived from stratified samples - that is, those well controlled for both age and sex. Figure 3, for example, shows the frequencies of elbow $\mathrm{OA}$ in three archaeological populations (Alaskan Inuit, Pueblo Indians, and Central California Indians). As can be seen, Inuit have the earliest onset and by far the greatest incidence of involvement. The extreme pattern displayed by Inuit, which is particularly characterised by erosion and ultimate destruction of the radiohumeral component, is quite unique. ${ }^{10}$ In general, in many (but not all) prehistoric populations, the incidence of elbow $\mathrm{OA}$ is greater than for contemporary groups; in contrast, the frequency of hip involvement is much lower.

The explanation for the differences in hip involvement in prehistoric groups compared with recent ones may lie in the relative age distributions. Hip disease is strongly correlated with advancing age. As prehistoric populations experienced a considerably shorter life expectancy, they would thus be expected to

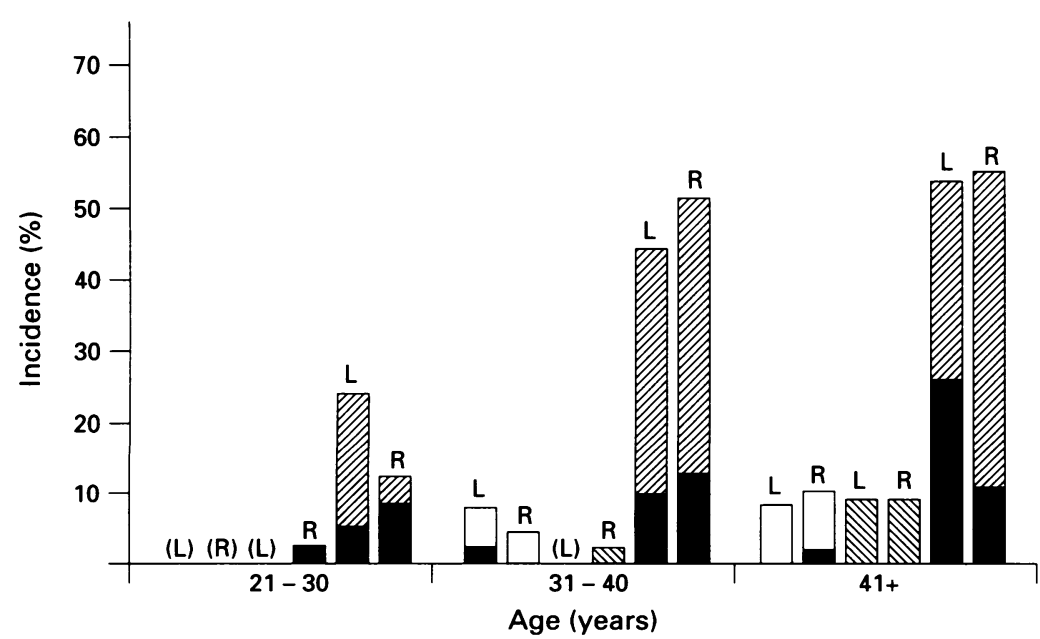

Figure 3 Incidence of osteoarthritis of the left $(L)$ and right $(R)$ elbows as shown in three archaeological populations: Ala-329 from Central California ( $\square$ ); Pecos Pueblo from the

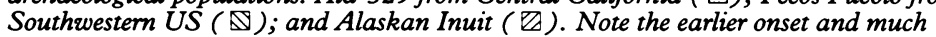
increased incidence among the Inuit. For each population, $\square$ represents severe disease and the remainder of any column represents moderate disease. show less hip involvement than is typically seen today. Moreover, as discussed below, the elbow may be more vulnerable to mechanical loading than the hip (which appears to be more prone to systematic factors). It thus becomes very tempting to try to correlate such patterns of OA with specific activities. For example, among Inuit highly intensified impulse loading associated with hunting (rowing, harpooning, etc.) might explain their unusually frequent and severe expression of elbow OA. As irresistible as such behavioural hypotheses may be, it must be recognised that anthropologists usually lack the precise data to make anything but very general (and usually untestable) behaviour based hypotheses.

What is clear, however, is that the pattern of degenerative disease within the elbow conforms well with a functional-mechanical aetiology of OA. Those areas presumably most subjected to mechanical loading show the greatest degree of variation. In addition, age appears to play considerably less of a role than is true for the shoulder. Inuit - as shown in figure 3-have a very high degree of elbow disease: more than any other archaeological population sampled to date. Inuit are known ethnohistorically to have experienced unusually high levels of mechanical loading associated with arctic hunting activities. ${ }^{53}$ We might thus reasonably infer that the frequent and severe levels of elbow OA result directly from this severe mechanical stress. However, the aetiological picture, as explicated by skeletal data, is not this unambiguous.

Mediaeval Sudanese Nubian groups are also thought to have engaged in a rigorous life style. However, they have considerably less elbow OA than is seen among Inuit but, conversely, show proportionately greater knee involvement. ${ }^{13}$ Indeed, in a general overview of the palaeoepidemiology of $\mathrm{OA}$ in the Americas, Bridges $^{54}$ could find little evidence of consistent patterns. Some populations show greater degrees of involvement in the knee (analogous to contemporary patterns), while others show patterns more similar to that of greater elbow involvement in Inuit. One general pattern does emerge from the archaeological data - the shoulder and hip are usually less severely involved than the knee or elbow.

Given the overall lack of systematic patterning in OA involvement among prehistoric groups, it would be unwise to draw unduly broad aetiological conclusions from these data. Certainly, as discussed above, even more hazardous are attempts to relate specific behaviours in prehistory to the onset of arthritic disease.

\section{Degenerative joint disease of the spine}

Numerous osteological studies have investigated the incidence of degenerative joint disease of the spine, particularly the manifestation referred to as vertebral osteophytosis or spondylosis of the fibrocartilagenous joints of vertebral body surfaces. ${ }^{13} 3033345556$ Less attention has been directed at involvement of the true synovial articulations of the dorsal 
apophyseal facets. ${ }^{13} 303356$ From these studies it appears that the pattern of involvement of spinal arthropathy, particularly vertebral osteophytosis, is more uniform between populations than that of peripheral involvement.

Vertebral osteophytosis is most common in those motion segments located at the peaks of the cervical and thoracic curves, in addition to throughout the lumbar area (fig 4). This pattern of involvement has been reported for numerous populations, including skeletal collections representing various populations of unspecified origin housed at the University of Witwatersrand and Cambridge University, ${ }^{41}$ United States Whites and Blacks, ${ }^{44}$ ancient Egyptians, ${ }^{55}$ Mediaeval Eastern Europeans, ${ }^{3+}$ Sadlermiut Inuit, ${ }^{33}$ Sudanese Nubians, ${ }^{13}$ Southeast US Indians, ${ }^{57}$ and Central California Indians. ${ }^{30}$

Although arthritis of the dorsal vertebral facets has been reported upon less frequently than spondylosis, similarities of expression also emerge from between group comparisons. These similarities include peaks of involvement in mid cervical and upper to mid thoracic segments and a gradual increase in incidence beginning in the lower thoracic region (T10-11) and continuing throughout the lumbar area. ${ }^{13} 333441$ Rather than attempting to explain spinal arthropathies as the result of specific activities, a more valid approach is to examine the pattern of lesions in terms of where they occur and to understand the general types of movement most likely to occur in particular motion segments. ${ }^{13} 58$ Thus while lumbar involvement probably results largely from compression caused by weight bearing, lesions in the cervical area are most likely caused by movement of all types.

It is evident from existing studies that peripheral articulations show a wider range of variation in incidence than do spinal joints. Although there are a number of limitations involved in interpopulation comparisons, this pattern does emerge. We suggest that the observed variation, especially that exhibited by the elbow and knee, may reflect differences in culturally based activities. However, the similarities in incidence, particularly those observed in the spine, occur as a function of species specific biomechanical parameters imposed by weight bearing and locomotion in an upright posture.

\section{Osteoarthritis in non-human primates}

Comparing the distribution of osteoarthritis in varied human populations provides a more inclusive perspective than concentrating strictly on contemporary groups. Even broader in its potential implications is the comparative study of non-human animals, most especially the non-human primates.

Degenerative lesions, as they are distributed in animals with different locomotory adaptations, can give insight into mechanical factors in the aetiopathogenesis of OA. Such a perspective has only recently been put to systematic use. ${ }^{23} 24$ One recent study ${ }^{59}$ surveyed 267 prosimians and 1250 anthropoid skeletons and found very low frequencies of OA. Among captive animals, the rates of involvement were quite low $(4.8 \%$ of prosimians and 3.7 of anthropoids) and even lower in free ranging animals $(0.8 \%$ among prosimians and $0.9 \%$ of anthropoids). Moreover, there was a difference in pattern: elbow and hip lesions were seen only in captive animals, but knee involvement was greater in free ranging individuals. Similar results were seen in our own study (in preparation) and another ${ }^{24}$ of a much smaller (but very well documented) series of free ranging chimpanzees from Gombe National Park. In this group, vertebral osteophytosis was also investigated, and no involvement whatsoever was seen in 483 vertebral body surfaces examined. Further reinforcing the total lack of vertebral osteophytosis was the observation that osteophytes

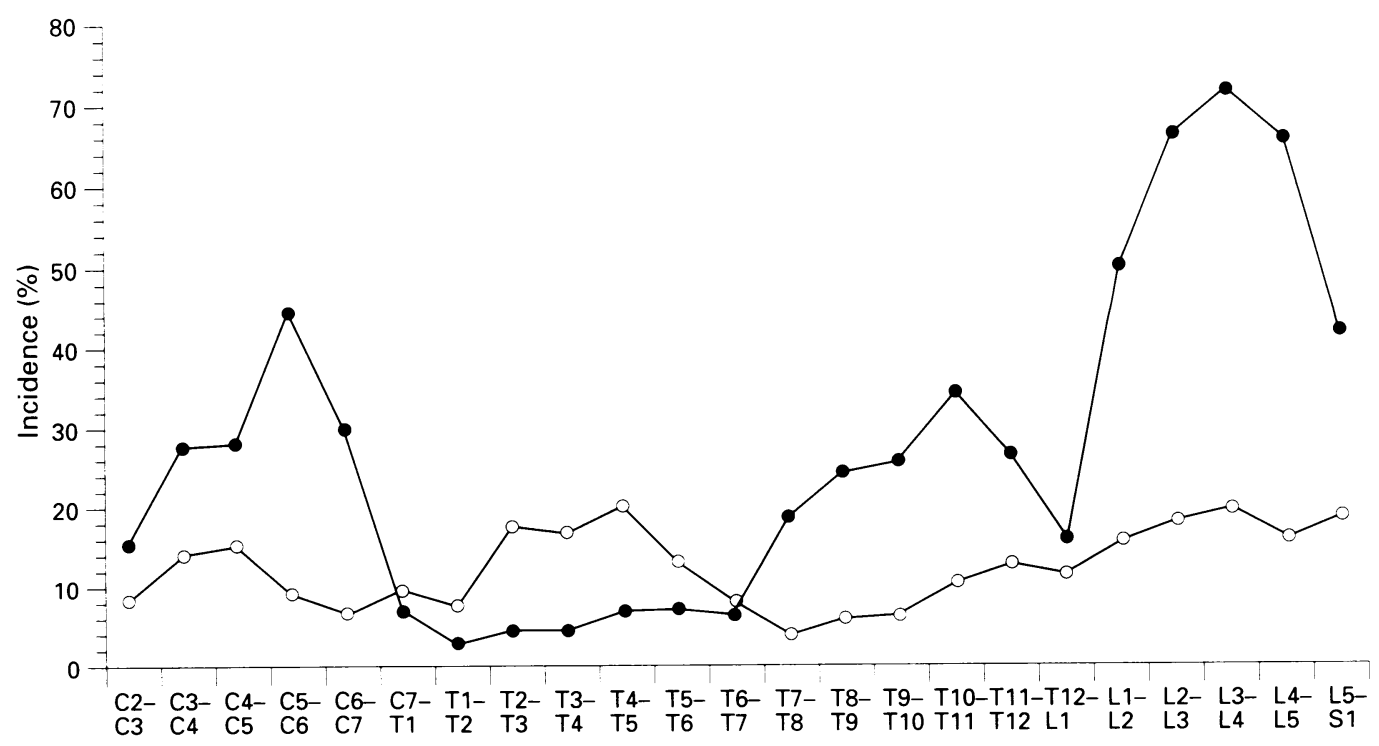

Figure 4 Incidence of vertebral osteophytosis (O) involving vertebral bodies compared with incidence of osteoarthritis ( $\bigcirc)$ involving the dorsal facet (apophyseal) joints (data from Mediaeval Nubian sample). 
did not occur even in individuals known to be quite old (in one case, an older female $>40$ years of age).

Another comprehensive study of three great ape species (free ranging chimpanzees, gorillas, and orangutans) ${ }^{23}$ also found low rates of degenerative involvement in the peripheral skeleton and spine. The one exception was observed in mountain gorillas, in which the incidence of vertebral osteophytosis approached $20 \%$. Finally, in a comparative pongid sample also from free ranging contexts, we found less than $1 \%$ vertebral involvement $(>2500$ surfaces examined) (paper in preparation). As with the study noted above, gorillas (lowland in this case) had a greater frequency of vertebral osteophytosis $(3.6 \%$ of vertebral body surfaces involved, and affecting close to $35 \%$ of individuals).

The explanation for the higher degree of involvement among gorillas compared with chimpanzees is thought to relate to the much greater body weight of the former species, ${ }^{23}$ up to four to five times that of chimpanzees. The differences in frequency of involvement in captive versus free ranging primates noted by Rothschild and Woods ${ }^{59}$ is also intriguing. Quite possibly, the variable patterns may be explained by differences in substrate surface or activity patterns.

Of even greater aetiological interest is comparison of the non-human primate data with the human pattern. In all cases, both for the spine and peripheral joints, humans consistently have markedly greater rates of degenerative joint involvement. For the spine, especially, the increased loading concomitant with bipedal locomotion may well provide the aetiological explanation. Certainly, vertebral osteophytosis is a ubiquitous human condition, seen in all cultural groups, and it is nearly pervasive after age 40 . Its almost complete absence in chimpanzees, and comparative rarity, even in the gorilla, argue for some fundamentally altered mechanical demands in the human species.

Always a concern, however, is the need to control for the influence of age. In most of the non-human primate studies noted above, the materials were obtained as 'wild shot' collections, and age was only very roughly estimated from often quite misleading observations made in the field ('young adult', 'old adult'). With no good criteria for aging adult skeletons of non-human primates, this lack of age control persists as a major limitation.

Another possible confounding issue is the pattern of degenerative joint disease seen in Old World monkeys. Osteological study of baboons $^{60}$ and radiographic survey of macaques $^{23}$ have indicated a high rate of vertebral osteophytosis in these animals. As both are quadrupeds, it is difficult to explain why monkeys would have more spinal involvement than great apes (which are modified, larger quadrupeds). One speculation is that increased flexion and extension in the lumbar spine of monkeys may be an important mechanical factor.
The study of arthritic patterns in closely related animals (including humans) who differ in locomotory adaptations is one that holds considerable promise. However, the provisional data now available suggest we would be too optimistic if we expect comfortably simple patterns to emerge from this work.

\section{Suggested directions for future studies}

There are numerous areas on which osteologists can and should focus serious attention in future studies of OA. Critical to comparative studies is the well recognised need for standardisation of scoring techniques. In the past, investigators have used a variety of methods for scoring OA, and there exists a general consensus regarding moderate and severe involvement. However, the diversity of scoring techniques frequently makes between population comparisons difficult; therefore discussion must, of necessity, remain superficial. The need for standardisation has frequently been the topic of informal discussion among palaeopathologists, and attempts aimed at improving the situation have been made. ${ }^{61}$

Another recognised need is increased access to surgically derived, macerated speicmens of arthritic joints. Such specimens, accompanied by detailed patient histories (age, occupation, symptomology) would be invaluable tools in helping osteologists assess the aetiopathogenesis of $\mathrm{OA}$ and the impact of this disease in archaeological populations. Obviously, osteologists must rely upon clinical colleagues to provide such materials with patient consent. Perhaps, with increased awareness of this need within the medical community, such specimens will be collected more systematically.

Non-human studies also would be tremendously aided by greater availability of macerated skeletons of captive animals, particularly non-human primates. In the United States, remains of zoo animals are most commonly donated to universities for dissection and the skeletons are almost never available for systematic study. If zoo derived specimens were made available, along with information pertaining to age at death, habitat design, substrate materials, and activity patterns, osteologists could begin to delineate those factors important to the development of OA in non-human primates. This ability would be greatly enhanced through comparisons with remains of free ranging primates. The small sample of 14 chimpanzees from $\mathrm{Dr}$ Jane Goodall's study group in Tanzania has been invaluable because of existing, often detailed, life history information and known or approximate age at death of individuals. Plans are now under way for the collection of chimpanzee and other primate remains from groups under study in the Kibale National Park, Uganda. Field researchers are increasingly aware of the importance of osteological analysis of their animals, and certainly there will be greater attention to the collection of bodies in the future. Unfortunately, at least in the case of chimpanzees, animals sometimes simply disappear and their fate remains unknown. 
Osteoarthritis is one of the most common ailments of modern humans. This disease, apparently, was also quite common in antiquity. By expanding the horizons of the database of OA in time and space, we also may be able to expand the horizons of our understanding of this often crippling disease.

1 Rothschild B. Radiologic assessment of osteoarthritis in dinosaurs. Ann Carnegie Mus 1990; 59: 295-301.

2 Stewart T D. The rate of development of vertebra osteophytosis in skeletal age identification. Leech 1958 28: $144-51$.

3 Chapman $\mathrm{F} \mathrm{H}$. Incidence of arthritis in a prehistoric Middle Mississippian Indian population. Indiana Acad Sci Proc 1962; 72: 59-62.

4 Anderson J E. The people of Fairty: an osteological analysis of an Iroquois ossuary. National Museum of Canada Bulletin, 193, Contributions to Anthropology, 1961-1962. Toronto: National Museum, 1963.

5 Angel J L. Early skeletons from Tranquility, California. Smithsonian Contrib Anthropol 1966; 2: No 1 .

6 Ortner D J. Description and classification of degenerative bone changes in the distal joint surfaces of the humerus. Am $\mathcal{F}$ Phys Anthropol 1968; 28: 139-55.

7 Rogers J, Watt I, Dieppe P. Arthritis in Saxon and medieval skeletons. $B M \mathcal{F}$ 1981; 283: 1668-70.

8 Bennike P. Paleopathology of Danish skeletons. Copenhagen: Akademisk Forlag, 1985.

9 Jurmain R D. Stress and the etiology of osteoarthritis. $A m$ f Phys Anthropol 1977; 46: 353-66.

10 Jurmain R D. Paleoepimemiology of degenerative joint disease. Med Coll Virginia $Q 1978 ; 14: 45-56$.

11 Jurmain $R$ D. The pattern of involvement of appendicular degenerative joint disease. Am $\mathcal{F}$ Phys Anthropol 1980; 53. 143-50.

12 Larsen C S. The anthropology of St Catherine's Island 3. Prehistoric human biological adaptation. Am Mus Nat Hist Anthropol Papers 1982; 57: 159-270.

13 Kilgore L. Degenerative joint disease in a medieval Nubian population [Thesis]. Boulder, CO: University of Colorado, 1984.

14 Bridges P S. Degenerative joint disease in hunter-gatherers and agriculturists from the southeastern United States. Am f Phys Anthropol 1991; 85: 379-91.

15 Lovell N. Spinal arthritis and physical stress at Bronze Age Harappa. Am f Phys Anthropol 1994; 93: 149-64.

16 Cobb S. The frequency of the rheumatic diseases. Cambridge: Harvard University Press, 1971.

17 Rothschild B M, Woods R J, Ortel W. Rheumatoid arthritis "in the buff:" erosive arthritis in defleshed bones. $A m \mathcal{F}$ Phys Anthropol 1990; 82: 441-9.

18 Leisen J C, Duncan H, Riddle J M. Rheumatoid erosive arthropathy as seen in macerated (dry) bone specimens. In: Ortner D J, Aufderheide A C, eds. Human paleopathology. Current synthesis and future options. Washington DC: Smithsonian Institution Press, 1991, 211-5.

19 Beitzke H. Ueber de sogen. Arthritis deformans atrophica. $Z$ Klin Med 1912; 74: 215-29.

20 Heine J. Uber die Arthritis deformans. Virchows Arch Pathol Anat 1926; 260: 521-663.

21 Chung E B. Aging in human joints. I. Articular cartilage. f Natl Med Assoc 1966; 58: 87.

22 DeRousseau C J. Osteoarthritis in rhesus monkeys and gibbons. $A$ locomotor model of joint degeneration. Contributions to Primatology, Vol 25. Basel: Karger, 1988.

23 Lovell N C. An evolutionary framework for assessing injury and illness in nonhuman primates. Yearbook Phy Anthropol 1991; 34: 117-55.

24 Lovell N C. Patterns of injury and illness in great apes. A skeletal analysis. Washington DC: Smithsonian Institution Press, 1990.

25 Rothschild B M, Woods R D. Reactive erosive arthritis. $A m$ F Primatol 1991; 25: 49-56.

26 Jurmain R D. Trauma, degenerative disease, and other pathologies among the Gombe chimpanzees. Am f Phys pathologies among the Gom
Anthropol 1989; 80: 229-37.

27 Bourke J B. A review of the paleopathology of the arthritic diseases. In: Brothwell D L, Sandison A T, eds. Diseases in antiquity. Springfield IL: Charles C Thomas, 1967; in antiquity.

28 Rogers J, Waldron T, Dieppe P, Watt I. Arthropathies in paleopathology: The basis of classification according to most probable cause. $\mathcal{f}$ Archaeol Sci 1987; 14: 179-93.
29 Jurmain R D. The distribution of degenerative joint disease in skeletal populations [Thesis]. Cambridge: Harvard University, 1975 .

30 Jurmain R D. Paleoepidemiology of a Central California prehistoric population from CA-Ala-329. II Degenerprehistoric population from CA-Ala-329. II. Deg
ative disease. Am $\mathcal{F}$ Phys Anthropol 1990; 83: 83-94.

31 Pierce L C. A comparison of the pattern of involvement of degenerative joint disease between an agricultural and a non-agricultural skeletal series [Thesis]. Knoxville: University of Tennessee, 1987.

32 Burr D B, Martin R B, Schaffler M B, Jurmain R D, Harner E J, Radin E L. Osteoarthrosis: Sex-specific relationship to osteoporosis. Am f Phys Anthropol 1983;

33 Merbs C F. Patterns of activity-induced pathology in Canadian Inuit population. Archaeol Surv Canada 1983, Paper 119.

34 Swedborg I. Degenerative changes of the human spine. Stockholm: Osteological Research Laboratory, University of Stockholm, 1974

35 Todd $\mathrm{T} \mathbb{W}$. Age changes in the pubic bone. I: The male White pubis. Am $\mathcal{F}$ Phys Anthropol 1920; 3: 285-334.

36 Bass W M. Human osteology. A laboratory and field manual, 3rd edn. Columbia, MO: Missouri Archaeologica Society, 1987.

37 Katz D, Suchey J. Age determination of the male os pubis Am f Phys Anthropol 1986; 69: 427-35.

38 Lovejoy C O, Meindl R S, Pryzbeck T R, Mensforth R P. Chronological metamorphosis of the auricular surface of the ilium: A new method for the determination of adult the ilium: A new method for the determination of adult skeletal

39 Iscan M Y, Loth S R, Wright R K. Metamorphosis at the sternal rib end: A new method to estimate age at death in White males. Am f Phys Anthropol 1984; 65: 147-56.

40 Nathan $H$. Osteophytes of the vertebral column: An anatomical study of their development according to age, race, and sex with consideration as to their etiology and significance. $\mathcal{F}$ Bone foint Surg Am 1962; 44: 243-68.

41 Collins D H. The pathology of articular and spinal diseases. London: E Arnold, 1949.

42 Fischer A. Rheumatismus als Berufskrankheit. Acta Rheumatologica 1932; 4: 24-8.

43 Molleson T. The eloquent bones of Abu Hureyra. Sci Am 1994; 271: 70-5.

44 Solonen K A. The joints of the lower extremities of footbal players. Ann Chir Gynaecol 1966; 55: 176-80.

45 Brodelius A. Osteoarthritis of the talar joints in footballer and ballet dancers. Acta Orthop Scand 1961; 30: 309-14.

46 Lawrence J S. Rheumatism in coal miners. Part III: Occupational factors. $\mathrm{Br}$ F Ind Med 1955; 12: 249-61.

47 Lawrence J S, de Graff R, Laine V A. Degenerative joint disease in random samples and occupational groups. In: Jeffrey $M$ R, Ball J, eds. The epidemiology of chronic rheumatism, Vol 1. Oxford: Blackwell, 1963; 98-119.

48 Mankin H, Brandt K D, Shulman L E. Workshop on etiopathogenesis of osteoarthritis. Proceedings and etiopathogenesis of osteoarthritis. Proceedings

49 Roche L, Maitrepairre J, Lejune E, Mermet J. Les atteintes du membre superieur chez ouvriers travaillant au martea pneumatique. Arch Mal Prof 1961; 22: 57-61.

50 Ruffer M A, Rietti A. On osseous lesions in ancien Egyptians. F Pathol Bacteriol 1911; 16: 439-65.

51 Hodges D C. Temporomandibular joint osteoarthritis in a British skeletal population. Am f Phys Anthropol 1991; 85: 367-77.

52 Pfeiffer S. The skeletal biology of Archaic populations of the Great Lakes region. Archaeol Surv Canada 1977; Paper

53 Nelson R K. Hunters of the northern ice. Chicago: University of Chicago Press, 1969

54 Bridges P S. Prehistoric arthritis in the Americas. Annu Rev Anthropol 1992; 21 : 67-91.

55 Bourke J B. Trauma and degenerative diseases in ancien Egypt and Nubia. $\mathcal{F}$ Hum Evol 1969; I: 225-32.

56 Shore L R. On osteoarthritis in the dorsal intervertebra joints. Br F Surg 1935; 22: 833-49.

57 Bridges P S. Vertebral arthritis and physical activities in the prehistoric southeastern United States. Am $f$ Phys Anthropol 1994; 93: 83-93.

58 White A A, Panjabi M M. Clinical biomechanics of the spine. Philadelphia: J B Lippincott, 1978.

59 Rothschild B M, Woods R J. Osteoarthritis, calcium pyrophosphate deposition disease, and osseous infection in Old World primates. Am f Phys Anthropol 1992; 87: 341-7.

60 Bramblett C A. Pathology of the Darajani baboon. Am $\mathcal{J}$ Phys Anthropol 1967; 26: 331-40.

61 Waldron T, Rogers J. Interobserver variation in coding osteoarthritis in human skeletal remains. Int $f$ Osteoarchaeol 1991; 1: 49-56. 